\title{
Current Issues in Pharmacy and Medical Sciences
}

\author{
Formerly ANNALES UnIVERSiTATIS MARIAE CURIE-SKLODOWSKa, SeCTIO DDD, PHARMACIA
} on-line: www.umlub.pl/pharmacy

\section{Metabolic profile and morpho-functional state of the liver in rats with glutamate-induced obesity}

\author{
MARYANA KONDRO ${ }^{1}$, GALYNA MYKHALCHYSHYN², PETRO BODNAR ${ }^{2}$, \\ NAZARII KOBYLIAK ${ }^{2}$, TETYANA FALALYEYEVA ${ }^{3 *}$
}

\author{
${ }^{1}$ Danylo Halytsky Lviv National Medical University, Ukraine \\ ${ }^{2}$ National Bogomolets Medical University, Ukraine \\ ${ }^{3}$ Taras Shevchenko National University of Kyiv, Ukraine
}

\begin{abstract}
The aim of our study was to investigate effects of monosodium glutamate (MSG) neonatal treatment on metabolic profile and liver morpho-functional state in rats at 16-weeks of age. Our study confirms previously reported data that neonatal treatment with MSG, administered by subcutaneous injection, is able to induce obesity without hyperphagia, which is diagnosed by high Lee index and characterized by small corporal weight and naso-anal length. It was established that MSG neonatal treatment induced metabolic changes at 16 weeks of age, which manifested as disproportional laying of fat deposits with the development of visceral obesity. The level of adiponectin was decreased after MSG neonatal treatment. Also, we showed development of dyslipidemia and non-alcoholic fatty liver disease and impairment sensitivity of peripheral tissue to insulin.
\end{abstract}

Keywords: monosodium glutamate, obesity, metabolic syndrome, non-alcoholic steatohepatosis, adiponectin

\section{INTRODUCTION}

According to the latest WHO data 1.5 billion of adults in the world suffer from obesity and more than 350 million have susceptibility to it development. Approximately 20 million children under 8 years of age have problems with excess weight. In Ukraine, every fourth woman and sixth man suffers from overweight and obesity. USA takes the first place in the world for prevalence of obesity. In this country, the main factors contributing to the weight gain are widespread network of fast food restaurants and hypodynamic.

The well-known flavor enhancer - monosodium glutamate (MSG), E 621 is widely used in food industries. In 1968, a report appeared in the New England Journal of Medicine, describing a constellation of symptoms in patients who dined in one of the growing number of Chinese restaurants. The symptoms of the so-called «Chinese restaurant syndrome» included numbness, radiating to the back, arms, and neck; weakness; and palpitations [8]. Later reports included other symptoms, such as tightness,

\footnotetext{
Corresponding author

* Taras Shevchenko National University of Kyiv,

Volodymyrska Str., 64/13, Kyiv, 01601, Ukraine

e-mail: tfalalyeyeva@mail.ru
}

DOI: $10.12923 / \mathrm{j} .2084-980 \mathrm{X} / 26.4 / \mathrm{a} .05$ flushing, tearing, dizziness, syncope, and facial pressure [6].

Today role of MSG in the development of obesity in people who abuse with "fast food" is contradictory. Some scientists believe that this food additive causes metabolic disorders and weight gain [15], but others claim that use of MSG, even in large doses, is not harmful for health [7]. The aim of our study was to investigate effects of MSG neonatal treatment on metabolic profile and liver morphofunctional state in rats at 16-weeks of age.

\section{MATERIAL AND METHODS}

This investigation was performed in compliance with the "Principles of laboratory animal care" (NIH Publication no. 85-23, revised 1985) and the authors have received approval from the Animal Ethical Research Committee of Taras Shevchenko National University of Kyiv.

Rats were divided into 2 groups: I - control ( $\mathrm{n}=15)$ rats that received saline solution subcutaneously (s.c.) at postnatal days 2, 4, 6, 8 and 10; II - animals ( $\mathrm{n}=15)$ with glutamate-induced obesity (GIO), which were given a solution of MSG (4.0 mg/g body weight, s.c.) at same days as those of the control group.

After 16-weeks of age, all rats were analyzed on changes of body weight. Obesity was determined by Lee 
index, which was calculated as the cube root of body weight $(\mathrm{g}) /$ naso-anal length $(\mathrm{cm})$. Value of this index equal to or less than 0.300 was classified as normal. Rats presenting values higher than 0.300 were classified as obese.

A day before the experiment, the animals received no food but had free access to water. After decapitation blood and liver tissue samples $(5.5 \mathrm{~mm})$ were taken for biochemical and morphological studies. We removed and weighed visceral adipose tissue (VAT). To assess morphological changes in liver we used NAS (NAFLD activity score). Lipid extraction from liver was performed according to Folch et al. ELISA was used for determination of adiponectin serum level on commercial kits «BioVendor» (Czech Republic).

Statistical analysis was performed by using SPSS-20 software. Data are expressed as means \pm SD and percentage. Statistical comparisons between groups were conducted using Student's $t$ test (for continuous variables) and $\chi^{2}$ test for categorical variables. Significance was set at $\mathrm{p}<0.05$.

\section{RESULTS}

Table 1 shows the anthropometrical parameters in both groups. In rats with MSG neonatal treatment after 16 weeks we observed obesity in all animals (100\%) versus $3(20 \%)$ rats of control group $(\mathrm{p}=0.001)$. Obesity was confirmed by Lee index, values of which were higher in the MSG group as compared to the control group $(0.363 \pm 0.029$ vs $0.290 \pm 0.025 ; \mathrm{p}<0.001)$. But in MSG-treated group we found significant diminished body weight by $9.43 \%$ $(p<0.001)$ and naso-anal length by $23.72 \%(p<0.001)$ in relation to the control group. Nevertheless, we have found that MSG neonatal treatment leads to the development of severe visceral obesity, because total weight of VAT were significant higher in rats with GIO $(17.16 \pm 1.52 \mathrm{~g}$ vs $8.31 \pm 0.99 \mathrm{~g} ; \mathrm{p}<0.001)$.

Table 1 presents no significant difference between the transaminases levels and parameters of pigment metabolism in control rats and animals with GIO.

Dyslipidemia was found in all rats with GIO compared to controls $(\mathrm{p}<0.001)$. We observed significant higher concentrations of total cholesterol (Tchol) at 55.4\% $(\mathrm{p}<0.001)$, triglycerides (TG) at 206.9\% ( $<<0.001)$, cholesterol of very low-density lipoprotein (VLDL-C) and low-density lipoprotein (LDL-C) at 208.9\% $(\mathrm{p}<0.001)$ and $83.5 \%(\mathrm{p}<0.001)$ respectively, with decreased level of high-density lipoprotein cholesterol (HDL-C) at 33.1\% $(\mathrm{p}<0.001)$ in rats with GIO compared to control group.

For estimation of morphological changes in liver we used NAS (NAFLD activity score). All data summarized in Table 2. According to it, the total score $\leq 3$ eliminates non-alcoholic steatohepatitis (NASH) and confirmed sim- ple steatosis, which we found in $93.3 \%$ animals with GIO. In all cases diagnosed with macrovesicular steatosis, fatty droplets shifted nucleus to the cell periphery and occupied the area of $15-70 \%$. Mild steatosis (lipid accumulation 5-33\%) was found in 53.3\% and moderate (lipid accumulation $33-66 \%$ ) in $46.7 \%$ cases. Mean values severity of hepatosis in NAS score was $1.47 \pm 0.51$. In $60 \%$ of rats with GIO we diagnosed mild lobular inflammation, in $13.3 \%$ balloon degeneration. In one rat with experimental obesity we detected a terminal state because the sum of score was 4 . In the control group, we did not find pathological changes in liver (total NAS score was $0.0 \pm 0.0$ ).

The serum adiponectin levels decreased in rats with MSG neonatal treatment compared to control group $(2.69 \pm 1.08$ vs $7.28 \pm 2.27 \mu \mathrm{g} / \mathrm{ml} ; \mathrm{p}<0.001)$.

Table 1. Anthropometric parameters and metabolic profile of experimental rats

\begin{tabular}{|l|c|c|c|}
\hline & $\begin{array}{c}\text { Control } \\
(\mathrm{n}=15)\end{array}$ & $\begin{array}{c}\text { GIO } \\
(\mathrm{n}=15)\end{array}$ & $\mathrm{p}$ \\
\hline Weight, g & $380.3 \pm 26.03$ & $344.4 \pm 24.23$ & 0.001 \\
\hline Naso-anal lehgth, cm & $25.25 \pm 1.57$ & $19.26 \pm 1.43$ & $<0.001$ \\
\hline Lee index & $0.290 \pm 0.025$ & $0.363 \pm 0.029$ & $<0.001$ \\
\hline Visceral adipose tissue, g & $8.31 \pm 0.99$ & $17.16 \pm 1.52$ & $<0.001$ \\
\hline Adiponectin, $\mu \mathrm{g} / \mathrm{ml}$ & $7.28 \pm 2.27$ & $2.69 \pm 1.08$ & $<0.001$ \\
\hline Alanine aminotransferase, mkkat/l & $0.228 \pm 0.033$ & $0.211 \pm 0.031$ & 0.168 \\
\hline Aspartate transaminase, mkkat/l & $0.389 \pm 0.034$ & $0.377 \pm 0.041$ & 0.408 \\
\hline Total bilirubin, $\mu \mathrm{mol} / \mathrm{l}$ & $12.4 \pm 2.09$ & $12.7 \pm 1.53$ & 0.627 \\
\hline Indirect bilirubin, $\mu \mathrm{mol} / \mathrm{l}$ & $7.9 \pm 1.7$ & $8.1 \pm 1.06$ & 0.703 \\
\hline Direct bilirubin, $\mu \mathrm{mol} / \mathrm{l}$ & $4.4 \pm 0.91$ & $4.6 \pm 0.91$ & 0.692 \\
\hline Triglyceride, mmol/l & $1.15 \pm 0.27$ & $3.53 \pm 0.57$ & $<0.001$ \\
\hline Total cholesterol, mmol/l & $4.53 \pm 0.34$ & $7.04 \pm 0.26$ & $<0.001$ \\
\hline Very low-density lipoprotein, $\mathrm{mmol} / \mathrm{l}$ & $0.51 \pm 0.12$ & $1.58 \pm 0.26$ & $<0.001$ \\
\hline High-density lipoprotein, $\mathrm{mmol} / \mathrm{l}$ & $1.63 \pm 0.14$ & $1.09 \pm 0.19$ & $<0.001$ \\
\hline Low-density lipoprotein, $\mathrm{mmol} / \mathrm{l}$ & $2.37 \pm 0.22$ & $4.35 \pm 0.29$ & $<0.001$ \\
\hline
\end{tabular}

Data are expressed as mean \pm SD. $\mathrm{p}<0.05$ (Student's t-test).

Table 2. Liver morphology of experimental rats due to NAS score

\begin{tabular}{|l|c|c|c|c|}
\hline & $\begin{array}{c}\text { Steatosis } \\
(0-3)\end{array}$ & $\begin{array}{c}\text { Lobular } \\
\text { Inflammation } \\
(0-3)\end{array}$ & $\begin{array}{c}\text { Ballooning } \\
\text { Degeneration } \\
(0-2)\end{array}$ & $\begin{array}{c}\text { Total NAS } \\
(0-8)\end{array}$ \\
\hline Control & $0.0 \pm 0.0$ & $0.0 \pm 0.0$ & $0.0 \pm 0.0$ & $0.0 \pm 0.0$ \\
\hline GIO & $1.47 \pm 0.51$ & $0.73 \pm 0.59$ & $0.13 \pm 0.3$ & $2.33 \pm 0.81$ \\
\hline
\end{tabular}

Data are expressed as mean \pm SD. $p<0.05$ (Student's t-test).

\section{DISCUSSION}

Our study confirms previously reported data that neonatal treatment with MSG, administered by subcutaneous or intraperitoneal injection, is able to induce obesity without hyperphagia, which diagnosed by high Lee index and characterized by small corporal weight and naso-anal length [12]. This model of obesity in rats causes by alterations in hypothalamic arcuate nucleus and impairs leptin and insulin signaling in this region [3] resulting in hyperleptinemia and hyperinsulinemia. When the hypothalamic ventromedial nucleus and arcuate nucleus are destroyed in rats by treatment with MSG in the neonatal stage, obesity occurs as the rats grow [11]. Also, obesity with stunted growth in other studies was associated with decreased adrenaline-stimulated lipolysis, pituitary weight and impaired pituitary function resulted in atrophy of re- 
lated target organs such as the gonads, accessory sexual organs, thyroids, and adrenals [1].

The main finding of the present study was that MSG neonatal treatment induced metabolic changes in 16 weeks of age, which manifested as disproportional laying of fat deposits with the development of visceral obesity. Consistent with these results, other studies have shown similar changes in these parameters. Several studies showed that neonatal treatment with MSG induced some increases in carcass fat, cellular size, and weight of the epididymal adipose tissue [13], greater retroperitoneal and periepididymal fat mass in comparison to control rats [2].

Nagata et al. found that mice after neonatal treatment with MSG were observed to be obese but had no polyphagia, and were glycosuric by 29 weeks of age. The pathological study showed hypertrophy of the pancreatic islet. Their blood concentrations of glucose, insulin, Tchol and TG were higher than in the control mice at 29 and 54 weeks of age. It was recognized as a continuation of the condition of diabetes mellitus [10]. On the other hand in the early phase of obesity, the level of plasma glucose can be normal but associated with hyperinsulinemia [12] which indicates that insulin resistance is present and high insulin levels may be compensatory [5] due to direct hypersecretion of ? cells [4]. Our study found decreased levels of adiponectin after MSG neonatal treatment at week 16. As known this adipocytokine is one of the main regulators of peripheral tissues sensitivity to insulin.

Also, we showed development of dyslipidemia and NAFLD. This results in agreement with previous reports, that find in the livers of MSG mice, moderate centrilobular microvesicular steatosis, ballooning degeneration with Mallory bodies, and scattered infiltration of neutrophils and lymphocytes [14]. Lazarin Mde O. et al. postulated that the enhanced glucose-6-phosphate dehydrogenase activity observed in the livers of MSG-obese rats could be associated with liver fat accumulation and likely plays a central role in the mitochondrial defense against oxidative stress [9].

Our results suggest that neonatal MSG treatment in 16-weeks-old rats lead to the development of several clusters of metabolic syndrome such as visceral obesity, dyslipidemia, non-alcoholic steatosis and impairment sensitivity of peripheral tissue to insulin.

\section{REFERENCES}

1. Araujo P.E.: Activity increase associated with obesity induced by monosodium glutamate in mice. Amer. $J$. Physiol., 225, 4, 764-765, 1973.

2. Cunha N.V.: Cox-2 inhibition attenuates cardiovascular and inflammatory aspects in monosodium glutamateinduced obese rats. Life Sci., 11, 87, 375-381, 2010.

3. Dawson R.: Attenuation of leptin-mediated effects by monosodium glutamate-induced arcuate nucleus damage. Am J Physiol., 273, 1, 202-206, 1997.

4. de Souza C.T. et al: Insulin secretion in monosodium glutamate (MSG) obese rats submitted to aerobic exercise training. Physiol Chem Phys Med NMR., 35, 1, 43-53, 2003.

5. Defronzo R.A. et al: Glucose intolerance and aging: evidence for tissue insensitivity to insulin. Diabetes., 28, 12, 1095-1101, 1978.

6. Geha R. et al.: Review of alleged reactions to monosodium glutamate and outcome of a multicenter double-blind placebo-controlled study. J. Nutr., 130, 1058-1062, 2000.

7. He K. et al.: Association of monosodium glutamate intake with overweight in Chinese adults: the INTERMAP Study. Obesity., 16, 8, 1875-1880, 2008.

8. Kwok R.H.M: Chinese-restaurant syndrome. N. Engl. J. Med., 278, 20, 796, 1968.

9. Lazarin Mde O., Ishii-Iwamoto E.L., Yamamoto N.S.: Liver mitochondrial function and redox status in an experimental model of non-alcoholic fatty liver disease induced by monosodium L-glutamate in rats. Exp Mol Pathol., 91, 3, 687-694, 2011.

10. Nagata M. et al.: Type 2 diabetes mellitus in obese mouse model induced by monosodium glutamate. Exp Anim., 55, 2, 109-115, 2006.

11. Nakagawa T.: Effects of chronic administration of sibutramine on body weight, food intake and motor activity in neonatally monosodium glutamate-treated obese female rats: relationship of antiobesity effect with monoamines. Exp Anim., 49, 239-249, 2000.

12. Papa P.C. et al.: GLUT4 protein is differently modulated during development of obesity in monosodium glutamatetreated mice. Life Sci., 71, 16, 1917-1928, 2002.

13. Ribeiro Braga L.: Continuous and intermittent exercise: effects of training and detraining on body fat in obese rats. Arch Latinoam Nutr., 54, 1, 58-65, 2004.

14. Sasaki Y. et al.: Effects of bezafibrate in nonalcoholic steatohepatitis model mice with monosodium glutamate-induced metabolic syndrome. Eur J Pharmacol., 15, 662, 1-8, 2011.

15. Shi Z. et al.: Monosodium glutamate is not associated with obesity or a greater prevalence of weight gain over 5 years: findings from the Jiangsu Nutrition Study of Chinese adults - response by Shi et al. Br. J Nutr., 9, 1-7, 2010. 